\title{
Toward a New Industrial Organization? OSS in Economic and Managerial Perspective
}

\author{
Jean Michel Dalle ${ }^{1}$, Cristina Rossi ${ }^{2}$, and Francesco Rullani ${ }^{3}$ \\ 1 Universit'e Pierre et Marie Curie, Paris, France; jean- \\ michel.dalle@upmc.fr, \\ 2 Politecniico di Milano, Department of Management, Economics, and \\ Industrial Engineering \\ P.zza Leonardo da Vinci 32, 20133, Milano, Italy \\ \{cristina1.rossi\}@polimi.it, \\ 3 Copenhagen Business School (fr.ivs@cbs.dk)
}

\begin{abstract}
At present, an more and more users are running Open Source software (OSS) on their systems. Major companies, like IBM, Oracle, or Sun Microsystems, have now started to make significant investments in developing open communities and creating a portfolio of systems incorporating OSS applications into their design. Meanwhile, an increasing number of firms are entering the market by offering OSS-based solutions to their customers, often supplying a mix of proprietary and open solutions through hybrid business models. In this context, economists and management scientists are now moving beyond the state of puzzlement that has driven much of the initial attention towards OSS. Located in the context of OSS2007 in order to foster close and fruitful interactions with scholars from various other disciplines, this workshop aims at contributing to the current evolutions of the economic and managerial research agendas about OSS, and thus to provide, first, an assessment of where we - economics and management scholars - are about OSS, and, second, an analysis of the renewed directions in which we should consider inquiring further in the near future, focusing notably on business, production, diffusion and innovation models.
\end{abstract}

\section{Introduction}

In December 2006, Apache had a market share of $60.64 \%$ against $30.67 \%$ for its immediate competitor. Linux has already been adopted by approximately 29 millions of users. The market share of the Web browser Firefox is surging despite the preexisting dominance of Internet Explorer*. Major companies like Oracle have now started providing professional support on Linux. IBM, which had been promoting Linux offerings for years, has strengthened its commitment to openness, making

Please wse the following format when citing this chapier:

Dalle, J.M., Rossi, C. and Rullani, F., 2007, in IFIP International Federation for Information Processing, Volume 234 , Open Source Development, Adoption and Innovation, eds. J. Feller, Fitzgerald, B., Scacchi, W., Sillitti, A., (Boston: Springer), pp. $377-379$. 
significant investments in the development of communities and creating a broad portfolio of systems adopting open standards and incorporating open-source applications into their design. Sun's Java is open-source. And meanwhile, an increasing number of firms are entering the market by offering open-source-based solutions to their customers, often supplying a mix of proprietary and open solutions through hybrid business models.

It is time to acknowledge the fact that Open-Source software now belongs to the mainstream of the software industry, and that it is rapidly modifying major elements of its industrial organization.

In this context, economists and management scientists are now moving beyond the state of puzzlement that has driven much of the initial attention towards opensource software and related systems.

This workshop aims at contributing to the current evolutions of the economic and managerial research agendas about open-source software providing, first, an assessment of where we - economics and management scholars - are about OSS, and, second, an analysis of the renewed directions in which we should consider inquiring further in the near future, focusing notably on business, production, diffusion and innovation models.

For this reasons we thought about the OSS2007 conference as a perfect context to develop a close and fruitful discussion around these topics. If on the one hand the perspective of the workshop will be able to attract a large number of economists and managerial scholars, on the other hand the collocation at the OSS2007 conference will foster the participation of scholars from various other disciplines, and notably software engineering researchers, creating an interdisciplinary milieu and enriching the debate.

\section{List of topics}

The following list of topics displays a non-exhaustive sample of the possible themes:

1. Business models: OSS strategies of large and small software firms, sustainability of OSS-based business models, hybridization between commercial and free/open software, relationships between software firms and OSS communities (firms' contributions and strategies, role of so-called paid developers, role of networks, etc.), implications of OSS licensing, and of copyright and patent issues, etc.

2. Production models: specificities of the OSS production model and their economic and managerial consequences, allocation and coordination mechanisms, characteristics of projects and of project ecologies, modularity issues, etc.

3. Diffusion models: empirical evidence on OSS diffusion, typologies of users and of adoption motives, users' characteristics, role of users' communities, market dynamics of OSS and proprietary software, integration and competition of open and closed solutions, etc. 
4. Innovation models: open innovation, factors favouring the emergence of OSS-like innovation regimes, policies dedicated to the software and to other sectors, open-source technology transfer, etc.

5. Standardization and platform strategies.

\section{Organisation and scientific committee}

The Organization Committee is formed by Jean-Michel Dalle, Université Pierre et Marie Curie (jean-michel.dalle@upmc.fr) Cristina Rossi, Politecnico di Milano (cristina1.rossi@polimi.it)

Francesco Rullani, Copenhagen Business School (fr.ivs@cbs.dk)

The members of the Scientific Committee are:

Cristiano Antonelli, Professor, University of Turin, IT

Stefano Comino, Assistant Professor, University of Trento, IT

Linus Dahlander, Research Fellow, Imperial College London, UK

Jean-Michel Dalle, Professor, Pierre-et-Marie-Curie University, FR

Paul David, Professor, Stanford University, US; Oxford Internet Institute, UK

Lars Frederiksen, Research Associate, Imperial College London, UK

Alfonso Gambardella, Professor, Bocconi University, IT

Marco Giarratana, Assistant Professor, Universidad Carlos III, ES

Lars Bo Jeppesen, Assistant Professor, Copenhagen Business School, DK

Joachim Henkel, Professor, Technical University of Munich, GE

Hely Koski, Professor, Helsinki School of Economics, FI

Yuwei Lin, Research Associate, University of Manchester, UK

Alessandro Nuvolari, Research Fellow, ECIS, Eindhoven University, NL

Margherita Pagani, Adjunct Professor of Management, Bocconi University, IT

Lucia Piscitello, Professor, Polytechnic of Milan, IT

Alessandro Rossi, Assistant Professor, University of Trento, IT

Cristina Rossi, Assistant Professor, Polytechnic of Milan, IT

Francesco Rullani, Post-doc Fellow, Copenhagen Business School, DK

Philipp J.H. Schroeder, Assistant Professor, Aarhus School of Business, DK

Sonali Shah, Assistant Professor, University of Illinois at Urbana-Champaign, US

Dominique Torre, Professor, University Nice Sophia Antipolis, FR

Salvatore Torrisi, Associate Professor, University of Bologna, IT

\section{$4 \quad$ Program}

The workshop will be help of June $14^{\text {th }} 2007$. The program provides for four thematic section, in which three papers will be presented. Each paper will be commented by a discussant.

Professor Paul A. David (Stanford University and Oxford Internet Institute) will give the introductory talk to the workshop on the topic: "Social Science Research Approaches to FLOSS". 